\title{
Commercializing the laboratory: Faculty patenting and the open science environment
}

\author{
Kira R. Fabrizio $^{\mathrm{a}, *}$, Alberto Di Minin ${ }^{\mathrm{b}}$ \\ ${ }^{a}$ Haas School of Business, University of California, Berkeley, Berkeley, CA 94720, USA \\ ${ }^{\mathrm{b}}$ Berkeley Roundtable on the International Economy (BRIE), University of California Berkeley, Berkeley, CA 94720, USA
}

Received 17 August 2005; received in revised form 14 December 2007; accepted 8 January 2008

Available online 3 April 2008

\begin{abstract}
This paper investigates the relationship between patenting and publication of research results by university faculty members. Our study adds to the limited evidence on this topic with an empirical investigation based on a panel data set for a broad sample of university researchers. Results suggest that publication and patenting are complementary, not substitute, activities for faculty members. This is not consistent with recent concerns regarding deleterious effects of patenting on the research output of faculty members. Average citations to publications, however, appear to decline for repeat patenters, suggesting either a decrease in quality or restrictions on use associated in patent protection.
\end{abstract}

(c) 2008 Elsevier B.V. All rights reserved.

PACS: I28; 031; 032; 038

Keywords: Technology management; Intellectual property policy

\section{Introduction}

University research has traditionally been associated with norms of rapid disclosure of research results and an environment of knowledge sharing, co-authorship, and joint projects that contribute to cumulative learning and innovation (Dasgupta and David, 1994). The reward system for faculty provides incentives for being first to discover and disclose new research results, and valuable reputations are built on diffusion of these results among the scientific community. Faculty members therefore have the incentive to pursue impactful research prob-

\footnotetext{
* Corresponding author. Permanent address: Goizueta Business School, Emory University, 1300 Clifton Road, Atlanta, GA 30322, USA. Tel.: +1 404727 4198; fax: +1 4047276663 .

E-mail address: Kira_Fabrizio@bus.emory.edu (K.R. Fabrizio).
}

lems and disclose research results openly and quickly (David, 1998; David et al., 1992). These activities stimulate the cumulative research process by facilitating the generating of fundamental discoveries and the transfer of knowledge among researchers. These norms and incentives are being challenged by the increasing patenting of university research results. In this study, we examine the relationship between a faculty member's involvement in patenting research results and the quantity and quality of publications generated. Our goal is to evaluate the recent concerns that patenting negatively affects the generation and publication of academic research.

This is an important question because academic research results contribute substantially to the industrial R\&D process (Mansfield, 1991, 1995, 1998; Narin et al., 1997). To varying degrees, respondents in all industries report that a significant percentage of their product 
and process innovations could not have been developed without academic research, or would have been substantially delayed. University research was reported as an important source of new projects for $31 \%$ of respondents and an important source of information for $36 \%$ of respondents (Cohen et al., 2002). In their survey of R\&D managers across many industries, Cohen et al. (2002) find that the most important channel for knowledge transfer from universities or government labs is publication of the research, followed by informal exchange, public meetings or conferences, and consulting. Patents were ranked as one of the least important transfer channels. ${ }^{1}$ Therefore, it is important both that academics continue to pursue fundamental research question and that they continue to publish their research findings.

There is reason to believe that the influence of patenting and commercialization activity on university researchers has grown in recent years. Since the late 1970s, the university research environment has changed dramatically. Policy changes, such as the Bayh-Dole Act of $1980,{ }^{2}$ encouraged commercialization of university research results by standardizing policies granting intellectual property rights to university researchers for outcomes of federally under research. ${ }^{3}$ At the time, federally funded research made up approximately $70 \%$ of university research. ${ }^{4}$ In addition, sources of academic research funding shifted substantially from the 1970s to the 1980s to include more industry funding and less government funding (Mansfield, 1995). ${ }^{5}$ Universities underwent organizational changes to attempt to better promote the commercialization of university research

\footnotetext{
${ }^{1}$ The pharmaceutical industry stands in contrast to these generalizations, with more knowledge transfer through the information disclosed in patents.

2 Patent and Trademark Act Amendments (P.L. 96-517).

${ }^{3}$ See Jaffe (2000) and Mowery and Ziedonis (2001) for a more extensive history of the policy changes.

${ }^{4}$ University faculty members do hold patents from prior to the passage of the Bayh-Dole Act. Some of these inventions were not patented through the university (i.e. they were patented by firms with which the faculty member worked or they were patented by the faculty person individually and not assigned to the university). However, even before the Bayh-Dole Act, universities could and did patent some inventions from faculty research. For example, the famous Cohen and Boyer patent on recombinant DNA technology was applied for in 1979 and is assigned to Stanford University. The importance of the Bayh-Dole Act is that it streamlined and standardized the rights of universities with respect to intellectual property stemming from federally funded research.

5 Industry funding of university research increased from $\$ 630$ million to $\$ 1.896$ billion between 1985 and 1998 , university-industry joint R\&D centers grew $60 \%$ during the 1980 s, and the number of university offices of technology transfer increased more than $800 \%$ between 1980 and 1995 (Cohen et al., 2002).
}

results (Argyres and Leibeskind, 1998). In response to these policy, institutional, and market changes, patenting by university researchers increased dramatically in the last two decades (Henderson et al., 1998a,b). This increase in patent volume was accompanied by a significant increase in the number of universities that were patenting innovations Henderson et al. (1998a). ${ }^{6}$ Providing researchers with the incentive to patent their findings may encourage commercialization of research findings, as intended by the Bayh-Dole Act. However, the increased focus on patenting may also lead to increased secrecy, delayed publication, and a shift in faculty research effort and time away from scientific research and toward commercialization activities, thereby decreasing the production and/or quality of scientific publications.

The existing empirical studies that attempt to uncover the relationship between academic patenting and publishing activities have presented contradictory pictures. Several surveys of academic researchers have documented the secrecy, delay of publication, and re-focusing of research activities that accompany involvement in patenting and commercialization activities (Blumenthal et al., 1996a,b; Campbell et al., 2002). However, the few existing studies of individual research publishing and patenting activities have failed to find such a negative impact. Agrawal and Henderson (2002) examine the patenting and publishing of faculty members in two departments at MIT (Mechanical and Electrical Engineering), and find no relationship between patenting and the generation of publications, but do find that the number of citations to publications is positively related to the level of patenting, which they interpret as evidence that patenting is positively correlated with the impact of research. Azoulay et al. (2004) examine the publication activity of faculty members in the life sciences field and find a positive relationship between patenting and the generation of publication, but do not examine citations to the publications. Positive correlations between publishing and patenting can be found in recent empirical investigations of non-U.S. context (Breschi et al., 2005; Buenstorf, 2006; Looy et al., 2005). Interestingly, Buenstorf's investigation of publishing behavior of Max Plant Institutes' Directors show that the positive correlation

\footnotetext{
${ }^{6}$ Mowery and Ziedonis (2001) find that of the 224 universities with patents issued after 1980, 51 universities had 10 or more issued patents applied for between 1970 and 1980, 92 universities had fewer than 10 issued patents during 1970-1980, and 81 universities has no patents issued during 1970-1980. This indicates the significant entry of inexperienced and less experienced universities into the pool of patenting universities.
} 
between publishing and patenting is somehow weakened in the few cases where the disclosed inventions were commercialized.

This study extends the existing literature in several ways. First, we draw from a broad sample of institutions and fields in which patenting is occurring, rather than focusing on one institution or one academic area. We develop a matched sample of non-patenting faculty researchers, and employ researcher-level fixed effects to estimate the relationship between patenting and annual publications or average citations to publications. This generates results that are more generalizable than some of the other studies. Second, we investigate the differential impacts of university, industry, and unassigned patents. Third, we examine the possibility that the number of patents held has a curvilinear relationship with the number of publications generated. Finally, our analysis controls for current researcher quality differently than this existing work and results suggest that these controls are important.

Our findings are consistent with most of these studies, importantly contradict some results, and extend this body of literature. Results presented here indicate that publication and patenting are complementary activities, but the positive relationship between them declines with an increasing number of cumulative patents held by the faculty researcher. Although we caution against causal interpretation of these results, this evidence suggests that faculty researchers are not generating less scientific research or limiting the open publication of research results as they patent, with the possible exception of a few very patent-intensive faculty members. Results of the analysis of citations to faculty publications indicate that the number of citations to a faculty members' publications is related to the productivity of the researchers, but not substantially different following the first patent by the faculty member. In fact, the citation intensity falls as a faculty member repeatedly patents his or her research results. This is contradictory to the limited previous evidence. Although we are focused on average quality and impact of publications rather than the citation patterns associated with an individual paper, our results are consistent with the anti-commons hypothesis put forth and tested by Murray and Stern (2005).

The remainder of the paper is organized as follows. The next section considers the possible relationship between faculty publishing and patenting activities and develops the hypotheses to be tested. Section 3 describes our sample and data, summary statistics of which are reported in Section 4. Section 5 presents our empirical strategy and results with respect to the production of publications by faculty members. Section 6 continues by exploring the relationship between patenting and the number of citations to these publications. Limitations of the study are discussed in Section 7, and conclusions are provided in Section 8.

\section{How are patents and publications related?}

We focus our study at the researcher level, allowing us to explore individual trade-offs and complementarities between patenting and publication for faculty researchers. ${ }^{7}$ There are competing factors which may drive the relationship between patenting and publication in opposite directions. The null hypothesis is that faculty publication is unrelated to patenting: if the faculty member chooses to apply for patent protection for some of his research discoveries, this does not change his production of publications from what it would have been. The two alternatives we consider and test for are that publication and patenting may be either complementary or substitute activities for faculty members in U.S. universities.

\subsection{Patenting and publishing may be complements}

University researchers may experience some complementarities between patenting and publishing. First and foremost, the same research stream may naturally lead to publications and yield patents. Faculty researchers interviewed by Agrawal and Henderson (2002) stated that "most patentable research is also publishablepatentinten," and that the decision of whether or not to patent research is something that happens after the research process, not in the selection of research projects. The academic norm of rewarding priority in disclosure of research results provides incentive for rapid open publication of research results by faculty members (David, 1998). Although patents may be valued by the academic community, the reward structure remains primarily focused on publications. ${ }^{8}$ Therefore, faculty members with research results that are patentable and also publishable are likely to publish the results even if

\footnotetext{
${ }^{7}$ Note that this conceptualization is implicitly conditional on the faculty researcher remaining in academia. Career effects of university patenting is a topic of future research.

${ }^{8}$ Based on a study of French academics, Carayol (2004) finds that the usual academic reward system does not provide incentives for patenting by faculty members. "The reputational reward of patents within the academic community seems to be low: Career profiles and patent production are not related," (Carayol, 2004). This may be less true in U.S. universities, some of which have begun to focus on patenting as well as publication in promotion decisions.
} 
they are also patented, although they may wait until the patent application is filed to submit the publication. ${ }^{9}$

In addition, the experience of patenting, licensing, and working with the licensee to transfer technology may prompt additional research questions. As the licensee works to develop the patented innovation, the university researcher may learn or encounter challenges that point to new research questions. Academic researchers report that problems they work on in academic research often come from ideas and problems encountered during industrial consulting (Mansfield, 1995). A survey of scientists found that $65 \%$ of researchers reported that interaction with industry has influenced their research. One respondent commented, "There is no doubt that working with industry scientists has made me a better researcher. They help me refine my experiments and sometimes have a different perspective on a problem that sparks my own ideas" (Siegel et al., 1999). This involvement and feedback may produce additional publications and potentially additional patents. University researcher involvement in commercialization activities may also provide information to the researcher about the relative value of various research streams, much as research grants and consulting have, and continue to do (Feller, 1990). ${ }^{10}$

Patenting of university research by a faculty member may also increase incentives for that researcher to publish more articles related to the patented research. Publications may serve as a type of advertisement, increasing the awareness and knowledgability of the relevant scientific community with regard to the patented technology. This can raise the value of the patented research because it increases the legitimacy of the technology and creates a set of researchers who know about and may be interested in utilizing the patented research.

Finally, patenting, and the subsequent (potential) licensing revenue and industry involvement may allow a university researcher access to additional funding (either from licensing revenue or industry funding) that he could spend on additional equipment, researchers, and junior

\footnotetext{
${ }^{9}$ There is a 1-year grace period following publication during which a U.S. patent must be filed before the published research is considered in the public domain. In order to avoid potential problems, some university administrators and faculty have instituted a conservative policy of submitting the publication and patent at roughly the same time. A patenting MIT faculty member that we spoke with stated that there used to be conflict between open publication and patenting, but that they had solved this by waiting to submit their publication until they submitted their patent application.

${ }^{10}$ In addition, collaborating with industry researchers may facilitate placement of PhD graduates (Adams et al., 2005), which could lead to continuing research funding and collaboration.
}

faculty members, all of which could contribute positively to the publications and patents produced by the lab. The respondent quoted above stated, "Also, my involvement with firms has allowed me to purchase better equipment for my lab, which means I can conduct more experiments," (Siegel et al., 1999). This may be reflected in both an increase in the productivity of the university research and an increased lab size, with more researchers working under the inventing faculty member.

These drivers all lead to the expectation that faculty members that patent will subsequently generate more publications. Hence, our first hypothesis is

Hypothesis 1. The number of publications generated by a faculty researcher will be higher following the application for a patent by the researcher.

\subsection{Patenting and publishing may be substitutes}

Alternatively, there are several reasons that a university researcher involved in patenting might publish fewer articles than he or she otherwise would have. First, involvement in patenting and commercialization activities may detract from the researcher's time and attention paid to scientific research. As researchers become more involved in the patenting process, and spends time locating licensees for their patents or working with the licensee to transfer the technology, time spent doing research may be compromised. The analysis here cannot explore the effect of licensing or commercialization activities directly because we do not have data on these activities. However, these activities are likely to be positively correlated with patenting, and therefore the relationship between patenting and publishing may be confounded by the influences of licensing and commercialization activities.

Second, patenting and licensing changes the incentives faced by the faculty members. According to the traditional norms of academic promotion, faculty members are rewarded for novel, fundamental discoveries generated and openly published in the scientific literature. The possibility to license-patented research provides an incentive for researchers to focus more time on research projects with more commercial potential. This may encourage a shift of resources away from fundamental research and toward commercially oriented research at the expense of more basic, fundamental, and publishable research projects.

Third, growing awareness and attention paid to intellectual property concerns may make researchers more inclined to secrecy, and less willing to openly share and publish research results. Thursby and Thursby (2000) 
report that more than half of the firms responding to their survey include delay of publication clauses in at least $90 \%$ of their university contracts. Several surveys (Louis et al., 2001; Blumenthal et al., 1996a,b; Campbell et al., 2002) have found that industry funding, commercial goals, and patenting have led researchers to increase secrecy with regard to research methodology and results. Blumenthal et al. (1996a,b) surveyed companies that fund life sciences research at universities and found that $47 \%$ of the respondents reported that their agreements with universities occasionally require that the university protect the confidentiality of research results for longer than is necessary for a patent application. In addition, faculty themselves sometimes delay publication in order to protect the confidentiality or financial value of the results (Blumenthal et al., 1996a,b). This extends the desire for secrecy from the research result being patented to related results, methodologies, and streams of research.

These reasons combine to form our second hypothesis:

Hypothesis 2. The number of publications generated by a faculty researcher will be lower following the application for a patent by the researcher.

It may also be the case that the first few patents by a researcher provide many of the positive benefits of patenting, such as interactions with industry researchers, while faculty researchers who patent many of their research results may be afflicted with some of the negative influences of patenting, such as limited time or industry capture. Managing the patenting process for one patent that happened to come out of research being done by a researcher is substantially different than altering a research trajectory to focus on more patentable research projects. We therefore also examine the curvilinear relationship that may exist if the negative influences become more important as the number of faculty member patents increases:

Hypothesis 3. There is an inverted- $U$ relationship between the cumulative number of patents granted to a researcher and the number of publications by the researcher.

\section{Sample and data}

The empirical analysis relies on developing a sample of university researchers that have patented their research results and a corresponding sample of university researchers that have not patented research results.
By collecting publication and patent count data for a long time period, we are able to examine a given researcher over time, as well as compare that researcher with the non-patenting control sample. ${ }^{11}$

This analysis requires two data sets: data on patents for all faculty members in the inventor sample and data on publications for all faculty members in both the inventor and non-inventor (control) samples. We have constructed these data sets from existing public sources, making new use of data sets that have been exploited for other purposes by combining patenting and publication data at the individual researcher level with researcher characteristics. The patent data is collected using the NBER patent databases (Hall et al., 2001). Using information on the inventors and assignees for all U.S. utility patents applied for between 1975 and 1995, we create a panel data set of patent information for each inventor in our sample. Because the inventor name data field in this database is uncleaned, data construction requires manually searching the inventor database to identify all permutations (i.e. various abbreviations and misspellings) of a given name that were truly the same inventor and exclude others with similar or identical names. ${ }^{12}$ For each inventorsample faculty member, we assembled a panel data set of the number of successful university-assigned, unassigned, and industry-assigned patents applied for in each year. For each inventor and control sample member, we construct a data set containing the number of publications in each year from the Science Citation Index. ${ }^{13}$

For each member of the inventor and control sample, we also collect data on their field, current institution, the year in which they received their $\mathrm{PhD}$, and the degree granting institution. The first two of these data items are collected from web searches. The PhD date and institution come primarily from the UMI International Digital Dissertations database, which includes records of dissertations filed since 1861, including author name, title, subject, $\mathrm{PhD}$ granting institution, and $\mathrm{PhD}$ date. For faculty members that received their MD instead of $\mathrm{PhD}$, we also use the American Medical Association Physi-

\footnotetext{
11 A similar empirical approach has been taken by Buenstorf (2006), as they considered longitudinal patent and publication data to explore the effects of patenting, licensing, and commercialization on the productivity of researchers.

12 This was done manually by comparing the address, assignee, and technology class for all patents potentially attributable to each inventor and excluding those patents that did not fit the profile of the inventor in the sample. A similar method, automated for application to a much larger sample, is described by Trajtenberg (2005).

${ }^{13}$ The source we used is the ISI Web of Knowledge online at http://isi3.isiknowledge.com/portal.cgi/wos.
} 
cian Select, which provides biographical information on members of the medical profession. Finally, for faculty members who do not appear in either of these databases, we relied on information from their web page or other web-based information.

\subsection{Faculty inventor sample}

Our goal for the inventor sample is for the sample to represent the fields in which university researchers are patenting and not limit our sample to researchers at one or a few universities. This allows for a broad, but unbiased, exploration of patenting behavior. We begin with a random sample of inventors on university-assigned patents. We then verify that they are indeed faculty members, and collect the necessary data for each.

We draw the sample of university inventors from the NBER database of patents and inventors (Hall et al., 2001). For the 23,930 university-assigned patents applied for between 1975 and 1995, there are 26,880 unique first name-last name combinations for inventors listed. Of these, there are 11,642 unique names that appear as the first inventor on the patent. ${ }^{14} \mathrm{~A}$ random sample of 400 of these 11,642 inventors was selected. A closer examination of these names yielded a sample of 384 that were truly unique. Based on web searches of the inventor name and assignee institution, we attempted to locate the inventor, confirm that he or she is a faculty member, and collect information on date of $\mathrm{PhD}$, position held, gender, and departmental affiliation of the inventor. Of these 384, 230 faculty inventors were found and confirmed as faculty. ${ }^{15}$ Others were not found, working in industry, non-faculty, retired or deceased prior to 1995, or located outside the U.S. For each of the 230 remaining inventor sample members, we collect data on publications and citations and $\mathrm{PhD}$ date. A common

\footnotetext{
${ }^{14}$ We found that it was much easier to locate information on the first inventors, which is why we use this in the selection of the sample. This may introduce some bias. It is possible that being first on a patent represents heading up the team of inventors, and so may also indicate some success in research. However, in some fields the lab director appears last on the patent. Correspondence with university inventors in several fields indicate that the meaning of first inventor varies by field. It is true that university inventors who ever appear as the first inventor on a patent are, on average, inventors on more patents. For this reason, our sample can be seen as composed on university researchers who are more heavily involved in patenting. This may limit the generalizability of our results. However, for the goal of evaluating potential negative effects of patenting activity, if may be the most appropriate sample.

15 Although manually verifying each inventor is time consuming and necessitates a limited sample size, the alternative pursued by Azoulay et al. (2004) is to drop individuals who seem to drop out of academia based on their publication record.
}

name prevented collection of publication data for 39 of these people, and no $\mathrm{PhD}$ date information was available for 25 of them.

\subsection{Control sample}

For each of the 166 remaining inventors in the sample, we select the faculty member currently in the same department at the same institution with the closest $\mathrm{PhD}$ date that IS NOT recorded as an inventor on any U.S. patents. ${ }^{16}$ Similar matching between inventors and non-inventors has been used in other empirical investigators. Two studies replicate the already cited study by (Agrawal and Henderson, 2002) in two European institutions: Buenstorf (2006) compares publication behavior of inventor and non-inventor Directors of the Max Plant Institutes in Germany, while Looy et al. (2005) focus on the K.U. Leuven in Belgium. A more similar crossinstitutional analysis is attempted in Breschi et al. (2005), where the authors look at the entire population of patenting faculty from Italian universities, matching them with non-inventors from the same disciplinary fields. Each of these three studies construct their control groups matching inventors with non-inventors belonging to the same disciplinary fields and with similar $\mathrm{PhD}$ years.

For each control member, we also collected information on publications and $\mathrm{PhD}$ date. For eight of the inventors, no acceptable match was available, and for eight of the control members, a common name prevented collection of publication data. In order to maintain our matched sample, dropping these control members required also excluding the inventor match from the analysis. This left us with a sample of 300 total researchers, evenly split between inventors and non-inventors.

By matching the control sample based on institution and department, we approximate a quality match as closely as possible. ${ }^{17}$ In addition, by matching at the institution level, the inventor and control sample members are operating under the same institu-

\footnotetext{
$\overline{16}$ For each faculty member selected for the control sample, a search was done on the U.S. Patent and Trademark Office (USPTO) website for matching inventors. If any inventors were found that could reasonably be judged to match the faculty member in question, based on name and location, a different member of the same department at the same institution was selected for the control sample. We also matched the faculty members based on position (i.e. Professor, Associate Professor, etc.).

17 This method of matched sample development is similar to that used, for example, by Trajtenberg et al. (1997) to match university and corporate patents, by Almeida (1996) to match the patents of foreign and U.S. firms, and by Remafedi et al. (1998) to match bisexual and homosexual high school students.
} 
tional environment. As Owen-Smith and Powell (2001) describe, institutional characteristics strongly influence the propensity of faculty members to patent. Matching on the $\mathrm{PhD}$ date allows approximate cohort matching. Additional criteria for matching based on characteristics indicating research quality, such as grant monies received, would be desirable as well, but such data was not available in this case.

Although the analysis below uses researcher level fixed effects to control for time-invariant heterogeneity across individuals and controls for the average life cycle pattern of publications, the control sample is useful as a comparison group. Since all faculty members in the inventor sample do patent at some point during their (observed) careers, their publication activity in the later years of their careers may be affected by the patenting. Therefore, the average life cycle pattern described by the publication activity of the inventor sample alone may be affected by patenting, and thus may not be an adequate control for the actual life cycle pattern. For example, if we were to only examine the inventor faculty members, and if patenting is associated with a subsequent drop in publication production, the life cycle effects will be bias (downward) in the later years and will pick up the drop in publications as part of the "natural" life cycle of faculty members. Likewise, if patenting is associated with a subsequent increase in publications, the increase will appear to be part of the common life cycle. In either case, the coefficients on the patenting variable will be biased toward zero. Therefore, we use the control sample in the analysis, and include estimates using only the inventor sample for comparison.

\section{Summary statistics}

By constructing the non-inventor control sample to be as similar as possible (along observable dimensions) to the inventor sample, we arrive at a well-matched pair of samples. The comparative summary statistics for the control and inventor sample are reported in Table 1. There may be some remaining concern that faculty members engaged in patenting during their career may be doing inherently different work than the faculty members that never patent, resulting in unobserved heterogeneity across researchers in the sample. In the analysis below, we control for unobserved heterogeneity using researcher-level fixed effects.

We limit our observations to the year of and all years following the $\mathrm{PhD}$ date of each sample member. This results in 5461 observations at the researcher-year level. For the 1975-1995 sample period, our data covers 1545 patents by inventor sample inventors, 1184 of which are
Table 1

Summary of inventor and control sample, 1975-1995

\begin{tabular}{lcc}
\hline & Inventors & Non-inventors \\
\hline Number & 150 & 150 \\
Mean PhD date & 1973 & 1973 \\
Percentage in: & & \\
$\quad$ Mechanical Engineering (\%) & 7 & 7 \\
Computer Science/Electrical & 11 & 11 \\
$\quad$ Engineering (\%) & 31 & 31 \\
Medical (\%) & 12 & 12 \\
Chemistry (\%) & 17 & 17 \\
Biomedical/Genetics/ & & \\
$\quad$ Microbiology (\%) & 10 & 10 \\
Chemical Engineering/Materials & & \\
$\quad$ Science (\%) & 2 & 2 \\
Physics (\%) & 6 & 6 \\
Other Science-Plant and Animal & & \\
$\quad$ Sciences (\%) & 3 & 3 \\
Behavioral, Philosophy, Cognitive & & \\
$\quad$ Science (\%) & & \\
Percentage that are: & 75 & 76 \\
Professors (\%) & 11 & 13 \\
Assoc. Professors (\%) & 0 & 1 \\
Assistant Professors (\%) & 9 & 4 \\
Professors Emeritus (\%) & 5 & \\
Research Professors (\%) & & \\
\hline
\end{tabular}

university-assigned, 274 are assigned to corporate entities, and 87 are unassigned. A histogram of the number of patents held by the faculty inventors in our sample is displayed in Fig. 1 and the summary statistics of the number of patent by type of assignee are reported in Table 2 . The distribution of the number of patents from 1975 to 1995 is highly skewed toward one or a few patents (18 of the 150 faculty inventors hold only one patent), while a few inventors hold many patents (five faculty inventors hold 50 patents or more, while only one holds more than 100

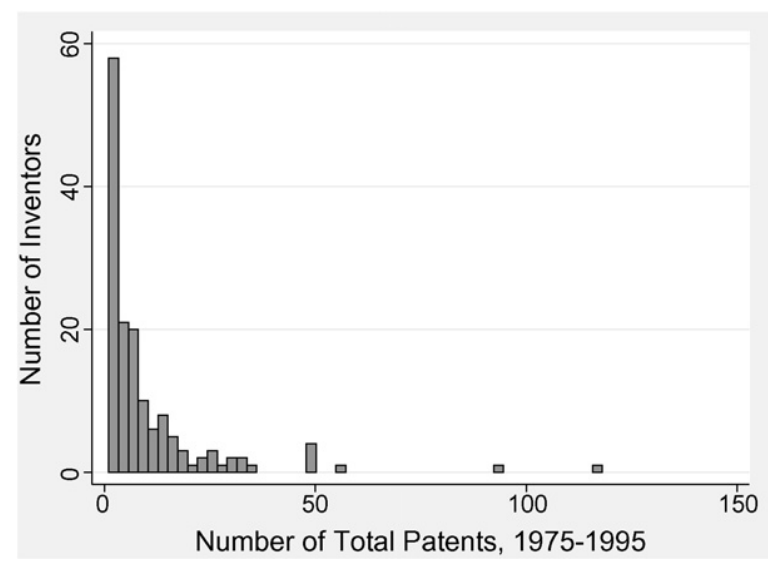

Fig. 1. Histogram of total patents per inventor. 
Table 2

Summary statistics of total patents per faculty inventor by type

\begin{tabular}{llcrr}
\hline & Minimum & Maximum & Mean & S.D. \\
\hline University patents & 1 & 117 & 7.9 & 12.6 \\
Industry patents & 0 & 58 & 2.0 & 5.8 \\
Unassigned patents & 0 & 25 & 0.6 & 2.4 \\
All patents & 1 & 118 & 10.5 & 15.4 \\
\hline
\end{tabular}

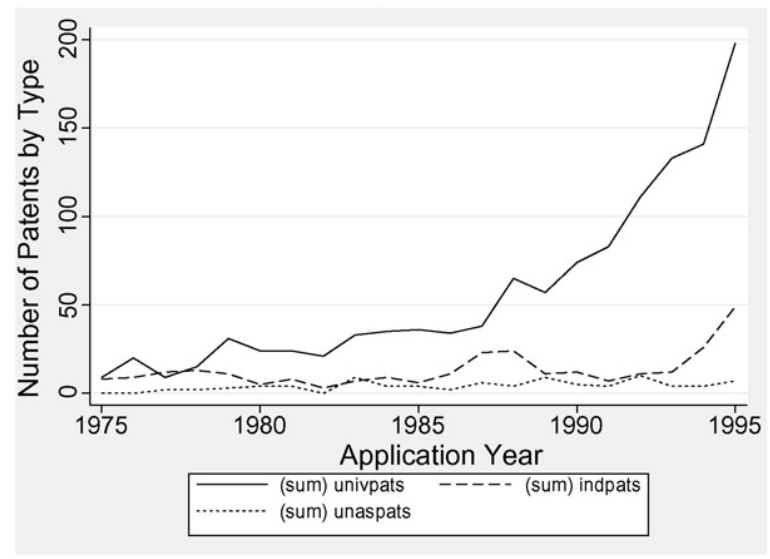

Fig. 2. Number of sample inventor faculty patents by assignee type.

patents) ${ }^{18}$ Over the $1975-1995$ period, the average number of university patents per year per inventor increased from about two to greater than three, while the number of industry-assigned patents increased slightly and the number of unassigned patents remained approximately constant (see Fig. 2).

For the 1975-1995 period, our data cover 17,063 publications for members of the inventor and control sample. Fig. 3 displays a histogram of the number of total publications during this period held by sample faculty member. Although the distribution is skewed to the left, it is flatter and has more mass at the higher values than the histogram of patents above. ${ }^{19}$ Table 3 provides the annual and total summary statistics for the entire sample and by inventor status. A difference of means test for the number of publications per year for inventors and non-inventors suggests that those researchers holding a patent applied for between 1975 and 1995 generate significantly more publications per year than

\footnotetext{
18 The faculty member that holds more than 100 patents is a professor in the biochemistry department at the University of Wisconsin. He holds 28 patents that were applied for prior to the passage of the BayhDole Act.

19 This is consistent with the data summary reported by Agrawal and Henderson (2002), although the distribution of publications in their sample is noticeably flatter.
}

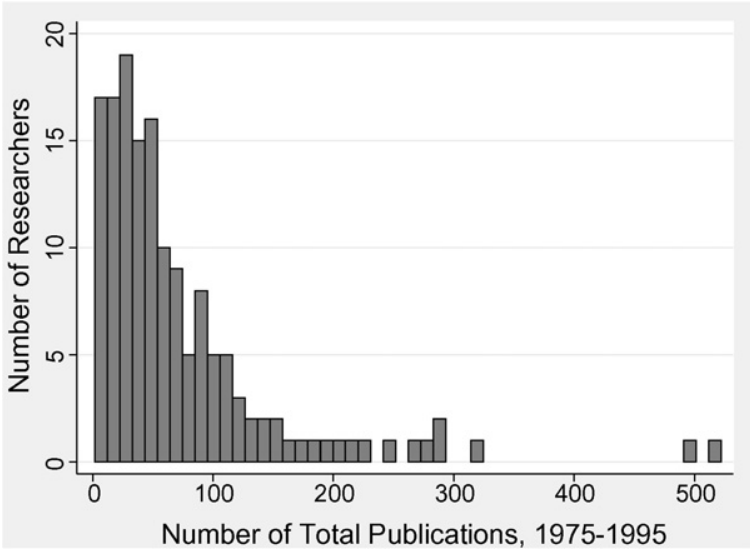

Fig. 3. Histogram of total publications per researcher.

non-inventors. ${ }^{20}$ Table 5 provides summary statistics for the variables used in the analysis, for the full sample as well as for the inventor and non-inventor subsamples.

\section{Empirical analysis and results}

With this data, we are able to test the competing hypotheses described above. Before assessing within faculty member changes in publications, it is interesting to briefly explore the differences across faculty members. Simple correlation coefficients across all sample members tell the basic story. There are significant positive correlations between publications and lagged publications, patents and lagged patents, publications and lagged patents, and patents and lagged publications (see Table 4). This suggests that in the cross-section, researchers with more patents also have more publications. In order to control for life cycle, field, and year effects, we investigate the relationship with regression analysis. Due to the count nature of the publication data, we employ a negative binomial specification. ${ }^{21}$ A negative binomial regression of the form:

$$
\begin{aligned}
& \left.E \text { (Publications }{ }_{i, t} \text { InventorID, YearsSincePhD, Field, Year }\right)^{=} \exp \left\{\beta_{1} \text { YearsSincePhD }_{i, t}+\beta_{2} \text { InventorID }_{i}\right. \\
& \left.\quad+\sum_{f} \gamma_{f} \text { Field }_{f}+\sum_{t} \alpha_{t} \text { Field }_{f} \text { Year }_{t}\right\}
\end{aligned}
$$

\footnotetext{
${ }^{20}$ Non-inventors publish on average 2.24 publications per year while inventors publish on average 3.99 publications per year. The difference is significant at the $1 \%$ level.

21 We first ran a Poisson specification, but a test for over dispersion rejected the constraint of the Poisson model at the $1 \%$ level, suggesting the need for the negative binomial specification.
} 
Table 3

Patent and publication summary statistics for inventors and non-inventors

\begin{tabular}{|c|c|c|c|c|c|c|}
\hline & \multicolumn{2}{|c|}{ Inventors } & \multicolumn{2}{|c|}{ Non-inventors } & \multicolumn{2}{|l|}{ All } \\
\hline & Mean & S.D. & Mean & S.D. & Mean & S.D. \\
\hline Annual publications & 3.99 & 5.18 & 2.24 & 2.96 & 3.12 & 4.32 \\
\hline Annual patents & 0.56 & 1.55 & 0 & 0 & 0.28 & 1.14 \\
\hline Total publications & 79.93 & 84.78 & 43.71 & 47.72 & 62.00 & 71.30 \\
\hline Total patents & 11.02 & 16.21 & 0 & 0 & 5.57 & 12.77 \\
\hline
\end{tabular}

Table 4

Correlations of current and lagged publications and patents

\begin{tabular}{|c|c|c|c|c|c|c|c|c|}
\hline & $\mathrm{Pub}_{t}$ & $\mathrm{Pub}_{t-1}$ & $\mathrm{Pub}_{t-2}$ & $\mathrm{Pub}_{t-3}$ & Pats $_{t}$ & Pats $_{t-1}$ & Pats $_{t-2}$ & Pats $_{t-3}$ \\
\hline $\mathrm{Pub}_{t}$ & 1 & & & & & & & \\
\hline $\mathrm{Pub}_{t-1}$ & 0.78 & 1 & & & & & & \\
\hline $\mathrm{Pub}_{t-2}$ & 0.77 & 0.78 & 1 & & & & & \\
\hline $\mathrm{Pub}_{t-3}$ & 0.72 & 0.78 & 0.78 & 1 & & & & \\
\hline Pats $_{t}$ & 0.30 & 0.30 & 0.28 & 0.30 & 1 & & & \\
\hline Pats $_{t-1}$ & 0.30 & 0.32 & 0.31 & 0.30 & 0.59 & 1 & & \\
\hline Pats $_{t-2}$ & 0.28 & 0.29 & 0.31 & 0.31 & 0.52 & 0.59 & 1 & \\
\hline Pats $_{t-3}$ & 0.26 & 0.28 & 0.28 & 0.31 & 0.41 & 0.49 & 0.57 & 1 \\
\hline
\end{tabular}

describes a reduced form of the observable determinants of publications in a year, where Publications $s_{i, t}$ is the number of publications in year $t$ for researcher $i$, InventorID $\mathrm{D}_{i}$ is a dummy variable equal to one in all years for researchers that are ever listed as an inventor on a patent, YearsSince $\mathrm{PhD}_{i, t}$ is equal to the number years since the PhD date for faculty person $i$ in year $t$, Field $_{i}$ is a dummy variable equal to 1 for faculty members in field $f$, and Field $_{f}$ Year $_{t}$ is a field-year dummy variable equal to one for observations of faculty members in field $f$ in year $t^{22}$ This interaction variable allows the year effects to vary by field.

Results of this pooled analysis are reported in Table $6 .^{23}$ As one would expect, the number of publications per year increases with the years since a researcher's $\mathrm{PhD}$ date, but at a decreasing rate over time. ${ }^{24}$ Confirming the difference in means reported above, inventor sample faculty members generate, on average, significantly more publications per year.

\footnotetext{
22 The fields of discipline for faculty in our sample are Mechanical Engineering, Computer Science/Electrical Engineering, Medical, Chemistry, Biomedical/Genetics/Microbiology, Chemical Engineering/Materials Science, Physics, Other Science, and Behavioral/Philosophy/Cognitive Science. Note that the matching for the control sample was done on much more detailed fields, such as genetics or inorganic chemistry.

23 Robust standard errors, clustered by individual, are reported, allowing for correlation across the observations for each individual.

${ }^{24}$ This is consistent with the findings of Levin and Stephan (1991) with respect to the publication life cycle of academic researchers.
}

Even when controls for recent publication activity are included, as in column (2), faculty members that are ever inventors on a patent generate more publications. These results suggest that the inventors in our sample are more prolific in terms of annual publications, to the order of 25-70\% more publications, than their non-inventor colleagues, consistent with the results of Meyer (2006). ${ }^{25}$

These pooled results suggest that there are some consistent differences across faculty members in the sample. In the following analyses, we control for the timeinvariant difference between researchers with researcher level fixed effects, estimating the relationship between changes in a researcher's annual publications and various measures of that researcher's patenting activity, controlling for field, year, and the overall career pattern of publication activity.

\subsection{Relationship between patenting and publishing activity}

In this section, we examine the evidence with respect to whether publication and patenting are complements or substitutes for individual faculty members. The conditional mean of the negative binomial publication function

\footnotetext{
25 A model allowing for self-selection into being an inventor, predicting inventorship using the number of patents held by the faculty members' degree granting institution, the first year in which the graduate degree granting institution employed 0.5 full time employees in a technology transfer office, and the prior patents of the faculty members' current institution, yields a consistent result.
} 
Table 5

Summary statistics for full sample, inventor sample, and non-inventor sample

\begin{tabular}{|c|c|c|c|c|c|c|}
\hline & \multicolumn{2}{|c|}{ Full sample } & \multicolumn{2}{|c|}{ Inventors } & \multicolumn{2}{|c|}{ Non-inventors } \\
\hline & Mean & S.D. & Mean & S.D. & Mean & S.D. \\
\hline Annual publications & 3.12 & 4.32 & 3.99 & 5.18 & 2.24 & 2.96 \\
\hline \#Cites/publication & 31.07 & 118.32 & 34.92 & 109.33 & 27.13 & 126.73 \\
\hline Cumulative publication & 28.75 & 46.24 & 36.57 & 56.57 & 20.78 & 30.49 \\
\hline Annual patents & 0.28 & 1.13 & 0.56 & 1.54 & 0 & 0 \\
\hline Annual university patents & 0.22 & 0.98 & 0.43 & 1.35 & 0 & 0 \\
\hline Annual industry patents & 0.05 & 0.41 & 0.10 & 0.58 & 0 & 0 \\
\hline Annual unassigned patents & 0.02 & 0.18 & 0.03 & 0.25 & 0 & 0 \\
\hline Cumulative \#patents & 0.34 & 1.27 & 0.67 & 1.72 & 0 & 0 \\
\hline Years since $\mathrm{PhD}$ & 14.62 & 9.42 & 14.87 & 9.54 & 14.37 & 9.29 \\
\hline
\end{tabular}

Table 6

Inventor and non-inventor faculty publications, pooled results

\begin{tabular}{|c|c|c|}
\hline & (1) & (2) \\
\hline Inventor_ID & $0.539(0.099)^{* *}$ & $0.226(0.049)^{* *}$ \\
\hline YearsSincePhD & $0.109(0.013)^{* *}$ & $0.028(0.009)^{* *}$ \\
\hline YearsSincePhD ${ }^{2}$ & $-0.002(0.000)^{* *}$ & $-0.001(0.000)^{* *}$ \\
\hline$\#$ pubs $_{t-1}$ & & $0.073(0.006)^{* *}$ \\
\hline$\#$ pubs $_{t-2}$ & & $0.056(0.007)^{* *}$ \\
\hline$\#$ pubs $_{t-3}$ & & $0.025(0.007)^{* *}$ \\
\hline Constant & $-0.055(0.347)$ & $0.223(0.310)$ \\
\hline Observations & 5461 & 4561 \\
\hline
\end{tabular}

Unit of observation is the individual-year for the 1975-1995 period. Dependent variable is the count of the number of publications in year $t$ and estimation is performed using a negative binomial model. Robust standard errors, clustered by individual, in parentheses; **significant at $1 \%$. All equations include field and field-year fixed effects.

for researcher $i$ in year $t$ is

$$
\begin{aligned}
& E\left(\text { Pubs } \mid \text { Patents, YearsSincePhD, } \mathrm{FE}_{i}\right) \\
& \quad=\exp \left\{\beta_{1} \text { YearsSincePhD }_{i, t}+\beta_{2} \text { PostPat }_{i, t}\right\}
\end{aligned}
$$

where YearsSince $\mathrm{PhD}_{i, t}$ is the same as above. The $\mathrm{FE}_{i}$ are research-level fixed effects, controlling for the unobserved heterogeneity across individuals, such as differences in ability or type of research. This effectively makes the estimation one of predicting with researcher differences. We estimate this equation using conditional fixed effects Poisson quasi-maximum likelihood estimation. This functional form is quite flexible and makes few restrictions, while allowing for correlation in the variance-covariance matrix to adjust the standard errors for the possibility of correlation across observations of a given individual. ${ }^{26}$

\footnotetext{
${ }^{26}$ For more information on conditional fixed effects Poisson quasi-maximum likelihood estimation, see http://econpapers.repec. org/software/bocbocode/s456821.htm.
}

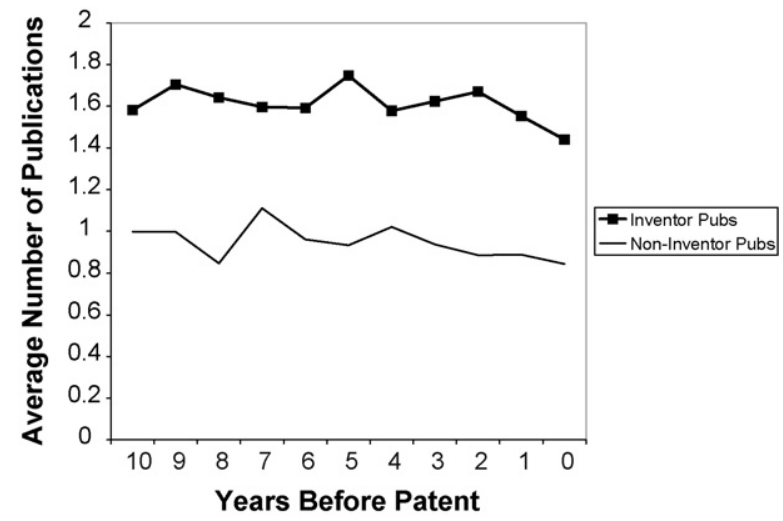

Fig. 4. Trends of pre-patent annual publications for control and inventor samples.

This empirical strategy relies on comparing the preand post-patenting publication activity of an inventor to evaluate whether or not there are significant changes in publication activity. As in other differencesin-differences work, this methodology relies on a control sample not affected by patenting, the non-inventor faculty members. In order for this approach to be valid, the pretreatment (here pre-patent) slope of the dependent variable must be indistinguishable between the treatment (inventor) and control sample. Based on a graphical investigation of the annual average number of patents per researcher in the control and inventor samples during the pre-patent period, the trends on the pre-period are the same for the two sets of individuals (see Fig. 4). ${ }^{27}$ We also test the similarity of pre-patent trends with a regression of the annual publication count in each pre-patent year on the relevant time variable (years since publication) and this variable

\footnotetext{
${ }^{27}$ We identified the pre-patent year for the control sample based on the first patent of the matched inventor.
} 
interacted with an inventor indicator variable, controlling for year effects, field-year effect, and individual-level fixed effects. The results indicate that the slope of the number of publications generated per year is not significantly different between the inventor and non-inventor sample during the pre-patent years, justifying the use of the difference-in-differences approach. The fact that the patent application(s) of each inventor occurs in a different year of his or her career allows us to distinguish between temporal shocks and changes associated with patenting.

We test three specifications of the patenting variable. The first, PostPat ${ }_{i, t}$, is an indicator for all years following the first patent of an inventor. The coefficient on this variable reflects a shift in the average publication production for the research from pre- to post-first patent. In some specifications we replace PostPat ${ }_{i, t}$ with either a variable equal to the number of patents in the currentyear, Patents $s_{i, t}$, or the cumulative number of patents held by the inventor, Cum.Patents $s_{i, t-1}$, and the square of this term. Including the contemporaneous patenting variable explores the short-term change in publications by the researcher. The cumulative number of prior patents allows an examination of the change in publication activity for faculty members that are repeat patenters. ${ }^{28}$

As a dependent variable, we employ the number of publications in year $t$ by researcher $i$, Pubs $i_{i, j}$. A $z$-test for significance of $\exp \left(\beta_{2}\right)$ indicates the significance of a within-researcher difference in publishing before and after a patent (or alternatively the significance of contemporaneous or cumulative impact effects). Inclusion of the non-patenting control sample members improves the estimation of the life cycle of publication described by the years since $\mathrm{PhD}$ variables, and also helps estimate the average year effects. ${ }^{29}$

Table 7 reports the results of the researcher fixed effects estimates for the annual number of publications. In all equations, the life cycle pattern (i.e. the relationship between years since $\mathrm{PhD}$ and publications) is the same as above. In the first equation, the coefficient on PostPat $_{i, t}$ is positive and significant, indicating that after

\footnotetext{
$\overline{28}$ Note that matching patent and publication data on the time dimension is tricky. We follow Agrawal and Henderson (2002) matching the publication year of articles with the application year of patents. In order to meet patent requirements, patenting researchers do not want to publish their research prior to applying for the patent, so the publication date will be contemporaneous with or later than the application date for related research. We evaluate the sensitivity of results to this timing assumption below.

${ }^{29}$ Note that for members of the control sample, the patenting variables are always equal to zero.
}

controlling for time-invariant unobserved researcher characteristics, publications per year are greater following a researcher's first patent by $20 \%$. The second equation includes the log of the current-year patents by the researcher, Patents $s_{i, t}$, the coefficient of which is positive and significant. Both of these results confirm Hypothesis 1 and contradict Hypothesis 2. Eq. (3) reports the results using the cumulative count of patents by the researcher through the prior year, Cum.Patents $s_{i, t-1}$, and this term squared. The linear term is not significant, very small in magnitude, and the squared term is small, negative and significant only at the $6 \%$ level. ${ }^{30}$ This does not provide support for Hypothesis 3 and suggest that only in the most extreme cases, in terms of the cumulative number of patents, is the relationship negative.

In order to make sure that our results are not sensitive to the nature of the control group, we reestimated Eq. (2) using only the inventors in the sample. The results, reported in column (4) are consistent with the results when we use the control sample. Not surprisingly, the magnitude of the coefficient is smaller because all individuals in the inventor sample are "treated" at some point. These results indicate that the number of publications is not lower, and in fact appears to be higher, following a patent by a researcher. $^{31}$

One potential concern is that the members of the control sample may be substantially different from the inventors in a way that biases the estimates of the control variables, including the life cycle effects. To investigate this, we re-estimated the equations allowing the life cycle profile, as reflected in the years since $\mathrm{PhD}$ variables, to differ from inventors and non-inventors by including the interactions of these variables with an inventor indicator variable. The results were robust to this modification. In fact, the interaction variables were not statistically significant, suggesting that the life cycle profiles of inventors and non-inventors are not substantially different after controlling for all other factors. To address this concern further, we re-estimated these equations with the sub-sample of inventing faculty (i.e. excluding the control group members entirely). The estimates corresponding to Eq. (2) are reported in Eq. (4)

\footnotetext{
30 The same relationship holds when we exclude the outlier with more than 100 patents during the period.

31 We also investigated the possibility of a possible "dip" in publication production preceding a patent by examining the relationship between publications and several years' leads and lags of patenting. There is no evidence suggesting any reduction in the number of publications produced in the 3 years prior to or following a patent.
} 
Table 7

Faculty publications as a function of patenting, fixed effects results

(1) (2)

$0.188(0.055)^{* *}$

Post-Patent

\#patents ${ }_{t}$

Cum.Patents $_{t-1}$

Cum.Patents ${ }^{2}{ }_{t-1}$

\#patents $s_{t-1}$

\#patents ${ }_{t-2}$

\#patents $s_{t-3}$

\#pubs $_{t-1}$

$\#$ pubs $_{t-2}$

$\#$ pubs $_{t-3}$

YearsSincePhD

YearsSincePhD ${ }^{2}$

$-0.002(0.000)^{* *}$

5461

$-0.002(0.000)^{* * *}$

$0.022(0.005)^{* *}$

(3)

(4)

(5)

Observations

5461

$0.118(0.010)^{* *}$

$-0.002(0.000)^{* *}$

5461

$0.007(0.007)$

$-0.000(0.000)$

Unit of observation is the individual-year for the 1975-1995 period. Dependent variable is the count of the number of publications in year $t$.

Estimation per-formed using Poisson quasi-maximum likelihood. Robust standard errors, clustered by individual, in parentheses; *significant at 5\%;

$* *$ significant at $1 \%$. All equations include researcher fixed effects.

and confirm that the control sample is not biasing the results. $^{32}$

The final equation in the table provides a comparison to the methodology employed by Agrawal and Henderson (2002), who do not find a significant relationship between the number of publications and the past patenting activity of the researchers investigated at MIT. In order to compare results with our sample to their analysis, we estimate an equation similar to the results they report, including the lagged number of publications for each researcher. By including the lagged publications in fixed effects regression of publications on patenting, the patenting variable can only pick up remaining variation in the number of current publications that is not related to lagged publications. Including this control decreases the magnitude of the coefficient on the patenting variable, but does not eliminate the significant positive relationship between patenting and publishing. ${ }^{33}$

\footnotetext{
32 One concern is that the number of applied research journals may be increasing more over time than the number of theoretical research journals, and patenting faculty members tend to do more applied work. If this were the case, we would expect to see publications by faculty members doing applied work (and patenting) increase over time. This would not be captured in the year effects, because those capture only the average year effect for the each field. To account for the possibility of differing year effects for the inventors and non-inventors, we reestimated Eqs. (1)-(3) using year effects interacted with an inventor dummy equal to one in all years for inventors. Results were robust to this flexibility.

${ }^{33}$ Fixed effects analysis with lagged dependent variables may result in biased estimates of the coefficients, and is especially problematic with count data models (see Blundell et al. (2002) and Wooldridge
}

Although the fixed effect controls for research-level heterogeneity, this analysis faces the additional challenge that patenting is an endogenous choice by the researcher. It may be the case that a faculty member decides to apply for a patent in a particular year in expectation of publishing a substantial set of research in the following year(s). We cannot rule out the possibility that the results reflect a strategic choice regard when a researcher patents their research results. Our results must therefore be interpreted with caution and should be interpreted as reflecting correlation, not causation. ${ }^{34}$

\subsection{Variation in patents}

To explore these results further, we include more detailed information about the patents held by these researchers. We characterize each patent as either university-assigned, industry-assigned, or unassigned. One might expect that university-assigned patents are more complementary to the faculty member's academic research, and so these patents might be associated with more publishing. Industry-assigned patents may rep-

(2000)). Therefore, we do not include lagged publications in our base models and provide these estimates here for comparison with Agrawal and Henderson (2002).

${ }^{34}$ In exploratory analyses, we experimented with instrumenting patenting using the cumulative number of patents applied for by each individual's colleague, meaning other individuals in the same field and at the same university. Although results were consistent with those reported here, the validity of this instrument is of concern. For example, if one believe that the patenting activity of colleagues affects a faculty member's publication productivity, then this is not a valid instrument. Due to these concerns, we elected not to report this analysis. 
Table 8

Faculty publications as a function of patenting, fixed effects results with assignee type

\begin{tabular}{lcc}
\hline & $(1)$ & $(2)$ \\
\hline Post-UniversityPatent & $0.162(0.056)^{*}$ & \\
Post-IndustryPatent & $0.029(0.076)$ & \\
Post-UnassignedPatent & $-0.103(0.160)$ & $0.027(0.006)^{* *}$ \\
\#UniversityPatents & & $-0.027(0.026)$ \\
\#IndustryPatents $_{t}$ & & $0.051(0.040)$ \\
\#UnassignedPatents & & $0.121(0.011)^{* *}$ \\
YearsSincePhD & $0.115(0.010)^{* *}$ & $-0.002(0.000)^{* *}$ \\
YearsSincePhD & & 5461 \\
Observations & $-0.002(0.000)^{* *}$ & \\
\hline
\end{tabular}

Unit of observation is the individual-year for the 1975-1995 period. Dependent variable is the count of the number of publications in year $t$. Estimation performed using Poisson quasi-maximum likelihood. Robust standard errors, clustered by individual, in parentheses; *significant at 5\%; **significant at $1 \%$. All equations include researcher fixed effects.

resent a deviation from traditional academic science, and may be associated with more of a drain on the researcher's time, and therefore act as more of a substitute to publications. However, as discussed above, industry-assigned patents by the researcher may also be associated with more industry interaction, which could prompt further research questions and may result in more publications.

We repeated the conditional fixed effects regressions with these more detailed counts of faculty patents, and results are reported in Table 8. Eq. (1) includes three dummy variables indicating the post-patent measure for university, industry, and unassigned patents. ${ }^{35}$ Interestingly, the only significant and positive coefficient is on the university patent variable. In Eq. (2), the variables of interest measure the number of patents of each type in the current-year. Again, university patents are the only type with a positive relationship with current publications. From this analysis, it is apparent that publications do not have the same relationship with all types of patents: university-assigned patents appear to be complementary to publication activity while industry and unassigned patents do not demonstrate a significant relationship with publications. However, this analysis does have the limitation that $76 \%$ of the patents by inventors in the sample were university-assigned, so the coefficients on the industry and unassigned patents may be not precisely estimated.

\footnotetext{
35 Note that these variables differ in a time dimension for a given researcher. If that researcher is an inventor on a university-assigned patent first, and later is an inventor an industry-assigned patent, the industry patent variable is switched to one at the later time period.
}

\section{Patenting and publication quality}

The results thus far demonstrate that faculty members who patent their research do not generate fewer publications after patenting. This discussion above also highlighted the possibility that patenting may be associated with a reallocation of research effort away from fundamental, basic science to more commercial, applied research projects. We investigate this related concern using the number of citations to a researchers' publications as a measure of the impact or quality of the research. High quality, fundamental, basic science will be cited more in future research because it is foundational, and therefore is relied upon in follow-on work. On the other hand, research aimed solely at a commercializable outcome is likely to be of less value to other researchers. If faculty members involved in patenting and commercialization activities are in fact changing the focus or compromising the quality of their research, the following hypothesis will hold:

Hypothesis 4. The number of citations to a faculty member's publications will be lower following a patent by the researcher.

In order to test this hypothesis, we collected data on the number of citations to publications in each year by each of the sample researchers. For the faculty members in our sample, this includes 812,996 citations. Our unit of analysis remains the research-year, so the dependent variable employed is the average number of citations per publication per year. ${ }^{36}$ We use the natural log of this value, $\ln \left(\operatorname{AvgCites}_{i, t}\right)$, in the analysis because the skewness of the distribution of the average number of cites. The general form of the equation to be estimated is as follows:

$$
\begin{aligned}
\ln \left(\text { AvgCites }_{i, t}\right) \\
=\beta_{1} \text { YearsSincePhD }_{i, t}+\beta_{2} \text { PostPat }_{i, t}+\beta_{3} \text { Pubs }_{i, t} \\
\quad+\beta_{4} \text { Pubs }_{i, t}^{2}+\sum_{t} \alpha_{t} \text { Field }_{f} \text { Year }_{t}+\gamma_{i} \mathrm{FE}_{i}+\varepsilon_{i, t}
\end{aligned}
$$

This analysis controls for the number of publications by researcher $i$ in year $t$ and this value squared. This is particularly appropriate for the citation analysis because (a) the count of publications will help control for time-varying researcher quality and (b) extremely prolific researchers

\footnotetext{
36 This is calculated as the total number of citations received as of May, 2003 by publications in that year divided by the number of publications made in that year for each researcher.
} 
Table 9

Inventor and non-inventor faculty average citations, pooled results

\begin{tabular}{lcc}
\hline & $(1)$ & $(2)$ \\
\hline Inventor_ID $_{\text {\#pubs }}$ & $0.348(0.113)^{* *}$ & $-0.023(0.077)$ \\
\#pubs $_{t}^{2}$ & & $0.409(0.037)^{* *}$ \\
YearsSincePhD $^{*}$ & $0.094(0.015)^{* *}$ & $-0.012(0.002)^{* *}$ \\
YearsSincePhD & $0.028(0.012)^{* *}$ \\
Constant & $-0.002(0.000)^{* *}$ & $-0.001(0.000)^{* *}$ \\
Observations & $1.376(0.518)^{* *}$ & $1.383(0.484)^{* *}$ \\
$R$-Squared & 5461 & 5461 \\
\hline
\end{tabular}

Unit of observation is the individual-year for the 1975-1995 period. Dependent variable is the natural log of the number of publications in year $t$, and estimation is performed using OLS. Robust standard errors, clustered by individual, in parentheses; *significant at 5\%; $* *$ significant at $1 \%$. All equations include field and field-year fixed effects.

may contribute less value added with each additional publication, and therefore each incremental publications may be cited less.

Before estimating the fixed effects model, it is useful to briefly examine differences across patenting and non-patenting faculty members in terms of the average number of citations received. Estimates of pooled regressions are reported in Table 9. Although on average inventors' publications are cited more heavily (Eq. (1)), this does not hold once the publication activity of the faculty member is controlled for. Including controls for the current publication production of the researcher, a reasonable proxy for researcher quality, the number of citations received by inventors is not distinguishable from the number received by non-inventors. Note that the expected curvilinear relationship between publications and average number of citations per publication is confirmed.

Results including researcher level fixed effects are reported in Table 10. We again consider three measure of relevant patenting activity: before and after the first patent for an inventor (PostPat $t_{i, t}$ ), contemporaneous patenting (\#patents $s_{i, j}$ ), and the cumulative number of patents by the inventor (Cum.Patents $i_{i, j}$ ). For each of the three, we estimate the equation with (Columns (4)-(6)) and without (Columns (1)-(3)) controls for current publication activity. Without the controls for current publications, there is evidence of a greater number of citations to publications in the year of a patent application (column 2). Once controls for the current publication activity are included (Columns (4)-(6)) the positive association between the average number of citations received and concurrent patenting is no longer significant and there is no significant change

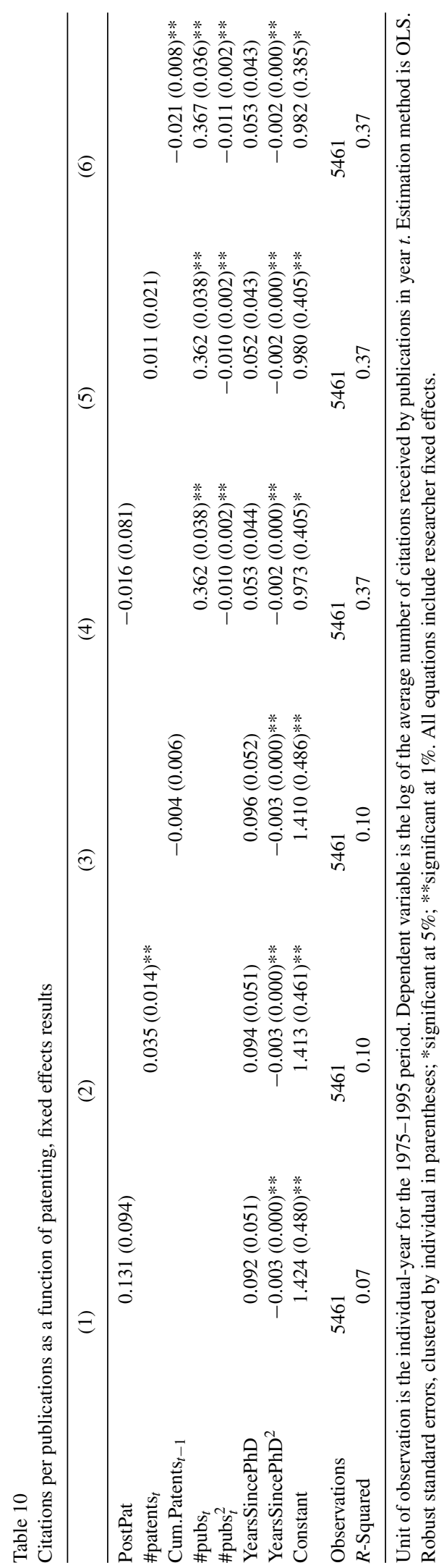


Table 11

Comparison to Agrawal \& Henderson results for citations per publication

\begin{tabular}{|c|c|c|c|c|}
\hline & Cum.Cites (1) & Cum.Cites (2) & Cites/Pub (3) & Cites/Pub (4) \\
\hline Deprec.Cum.Pubs $t_{t}$ & $0.005(0.000)^{* *}$ & $-0.000(0.000)$ & & \\
\hline Deprec.Cum.Patents $t$ & $0.021(0.008)^{* * *}$ & $-0.044(0.010)^{* *}$ & & \\
\hline$\#$ pubs $_{t}$ & & $0.096(0.002)^{* *}$ & & $0.139(0.017)^{* *}$ \\
\hline \#patents ${ }_{t}$ & & & $0.030(0.013) *$ & $0.008(0.012)$ \\
\hline \#patents $_{t-1}$ & & & $-0.045(0.025)$ & $-0.053(0.025)^{*}$ \\
\hline \#patents $_{t-2}$ & & & $0.012(0.018)$ & $0.001(0.022)$ \\
\hline \#patents ${ }_{t-3}$ & & & $-0.060(0.016)^{* *}$ & $-0.055(0.022)^{*}$ \\
\hline$\#$ pubs $_{t-1}$ & & & $0.020(0.006)^{* *}$ & $-0.016(0.009)$ \\
\hline$\#$ pubs $_{t-2}$ & & & $0.005(0.006)$ & $-0.028(0.007)^{* *}$ \\
\hline$\#$ pubs $_{t-3}$ & & & $-0.004(0.006)$ & $-0.009(0.007)$ \\
\hline YearsSincePhD & $0.134(0.005)^{* *}$ & $0.113(0.005)^{* *}$ & $0.108(0.015)^{* *}$ & $0.091(0.015)^{* *}$ \\
\hline YearsSincePhD ${ }^{2}$ & $-0.003(0.000)^{* *}$ & $-0.003(0.000)^{* *}$ & $-0.003(0.000)^{* *}$ & $-0.002(0.000)^{* *}$ \\
\hline Constant & $-1.412(0.042)^{* *}$ & $-1.300(0.042)^{* *}$ & $1.446(0.135)^{* *}$ & $1.383(0.132)^{* *}$ \\
\hline Observations & 5461 & 5461 & 4561 & 4561 \\
\hline
\end{tabular}

Unit of observation is the individual-year for the 1975-1995 period. Dependent variable in (1) and (2) is the log of the depreciated cumulative count of citation to publications through year $t$. Estimation method is negative binomial. Dependent variable in (3) and (4) is the log of the average number of citations received by publications in year $t$. Estimation method is OLS. Standard errors in parentheses, clustered by individual in (3) and (4); *significant at $5 \%$; **significant at $1 \%$. All equations include researcher fixed effects.

in average number of citations received following an inventor's first patent (Eq. (3)). However, the cumulative number of patents by the faculty members is significantly and negatively related to the number of citations received.

Therefore, the results testing Hypothesis 4 are mixed. The evidence suggests that there is no average change in citation intensity following an inventor's first patent. However, if a researcher patents repeatedly, then the average citation intensity is lower, suggesting a possible decline in research quality or impact. These results are contradictory to those reported in Agrawal and Henderson (2002). In their analysis of citations to publications, those authors regress the depreciated stock of citations on the depreciated stock of papers and the depreciated stock of patents. ${ }^{37}$ They find a positive coefficient on this measure of patenting activity. Eq. (1) in Table 11 provides a comparable analysis with our data set. The coefficient on the depreciated stock of patents is positive and significant, in agreement with Agrawal and Henderson's results. However, further analysis suggests that this result is not robust to controlling for current publication activity. Eq. (2) includes the current-year publications of the researcher. With this control, the evidence suggests a negative and significant relationship between the depreciated stock of patents and depreci-

\footnotetext{
37 Agrawal and Henderson use a $20 \%$ annual depreciation rate, and include citations, papers, and patents through the current year. We do the same here.
}

ated stock of paper citations, consistent with the results reported above.

Eqs. (3) and (4) examine this further using the average citations for the dependent variable and examining the relationship to several lags of patents and publications by the researcher. Recent and current counts of publications are highly correlated with average citations to current publications, perhaps reflecting the recent quality of the researcher, but current patents are not significant. This suggests that the citation of current publications may be more related to recent publication activity than to patenting. In addition, there is some evidence that during the years following a patent application, the average number of citations to a faculty member's publications falls (Eq. (4)).

\section{Limitations}

This empirical analysis attempts to make inferences about the factors influencing the publication behavior of faculty members over time. There are no doubt unobserved factors influencing both publishing and patenting for these individuals. We have attempted to provide analyses robust to these concerns by using researcher level fixed effects to control for unobserved heterogeneity across researchers, exploratory analysis using instrumental variables to instrument the endogenous decision to patenting, and confirming the robustness of the results to limiting the analysis to the sub-sample of faculty inventors. However, we caution 
against attributing strong causality to the results. Without further analysis of the mechanisms underpinning the noted increased in publication production following patenting, the reasons for such an increase remain speculative.

\section{Conclusion}

The Bayh-Dole Act and increasing collaboration between industry and university researchers have served to dramatically increase patenting by university faculty members. As patenting has grown, so has concern about the possible negative effects on the generation and publication of fundamental research results by faculty members. How the change in norms has impacted the open publication and use of university research results is a matter of concern for policy makers and firm managers in need of accessing university research results.

This research contributes to the existing literature by providing an empirical investigation of faculty patenting and publishing with a data set containing inventors from multiple fields at many institutions in many fields across many years. Our results confirm the results in some existing work, contradict others, and extend the existing literature. The results presented here are not consistent with the concern that the publication activity of faculty researchers would fall with increasing patenting activity. The annual number of publications by a faculty member is in fact higher following application for a successful patent, controlling for field, year, and time profile of publications by matched non-inventors. Again, we stress that this should be interpreted as a correlation, as we cannot test or assert causation from this analysis. This result is consistent with other recent studies of faculty patenting.

Interestingly, results here demonstrate that university patents (and not corporate or unassigned patents) drive the positive relationship. This suggests that the positive relationship is not attributable to academic researchers gaining new insights and ideas from working with industry researchers. If that were the case, we should expect to see at least an equal positive relationship between industry-assigned patents and faculty publications. Since the same research often underlies publications and patents, this result may indicate that the research embodied in university-assigned patents is closer to academic research, which yields subsequent publications. The results may also be driven by university technology licensing offices electing to patent the most promising research results, which are also associated with more publications, and passing on less promising results, which are then either patented without an assignee or picked up by a corporation that appears as the assignee on the granted patent. Further research into the mechanisms responsible for the differences across types of patents is needed to examine these possibilities.

The relationship between patenting and citations to publications suggests that there is not a large-scale shift to lower quality or less impactful research following an inventor's first patent. However, faculty members that repeatedly patent their research results generate publications that receive fewer citations. This may be an indication that these faculty members are in fact re-focusing their research on more applied or commercializable research, at the expense of fundamental science. It may also be a result of increasing intellectual property rights inhibiting the use of their published research results in follow-on studies. This evidence is contradictory to the limited prior evidence concerning the relationship between patenting and the quality or impact of faculty publications, but is consistent with the results of Murray and Stern (2005), who present an analysis of matched publication and patents covering the same research result. Their results suggest that citations to papers decrease when a patent related to the same research is granted. This is consistent with the interpretation that increasing patent protection to a faculty member's research results is associated with fewer citations to that individual's publications.

Comparing these results with Agrawal and Henderson (2002) suggests that the relationship between faculty patenting and publishing may be different for faculty members in general than it is for faculty at elite institutions, such as MIT. Perhaps one reason is that patenting, licensing, and commercialization activities may allow a faculty member access to more industry funding. MIT faculty may not be as constrained by limited funding as researchers at other schools, and they therefore benefit less from added access to funding. There are likely to be other institutional differences driving the variation in results as well. In a comparison between Stanford and Berkeley Electrical Engineering and Computer Science departments, Kenney and Goe (2003) find that a different attitude towards commercialization partially explains the more intense technology transfer activities at Stanford. In Europe, Debackere and Veugelers (2005) find convincing evidence that universities allocating a higher percentage of royalties to inventors are more effective in technology transfer activities. Further research will consider the alternative explanations for the noted increase in publications following a patent application, 
as well as an evaluation of possible differences across institutions of varying quality. Based on the evidence presented here, increasing faculty members' incentives to patent research results does not seem to be overwhelming the incentives for faculty members to publish their research.

\section{References}

Adams, J., Black, J., Stephan, P., 2005. Scientific teams and institutional collaborations: evidence from U.S. universities. Research Policy 34 (3), 253-257.

Agrawal, A., Henderson, R., 2002. Putting patents in context: exploring knowledge transfer from MIT. Management Science 48 (1), 44-60.

Almeida, P., 1996. Knowledge sourcing by foreign multinationals: patent citation analysis in the U.S. semiconductor industry. Strategic Management Journal 17, 155-165.

Argyres, N.S., Leibeskind, J.P., 1998. Privatizing the intellectual commons: universities and the commercialization of biotechnology. Journal of Economic Behavior \& Organization 35, 427-454.

Azoulay, P., Ding, W., Stuart, T., 2004. The impact of academic patenting on (public) research output. Working Paper.

Blumenthal, D., Campbell, E., Anderson, M., Causino, N., Louis, K., 1996a. Withholding research results in academic lifescience: evidence from a national survey of faculty. Journal of The American Medical Association 277 (15), 1224-1228.

Blumenthal, D., Causino, N., Campbell, E., Seashore, K., 1996b. Relationships between academic institutions and industry in the life sciences-an industry survey. The New England Journal of Medicine 334 (6), 368-373.

Blundell, R., Griffith, R., Windmeijer, F., 2002. Individual effects and dynamics in count data models. Journal of Econometrics 108, 113-131.

Breschi, S., Lissoni, F., Montobbio, F., 2005. The Scientific Productivity of Academic Inventors. Bacconi University, Mimeo.

Buenstorf, G., 2006. Commercializing Basic Science as a Competitor or Complement of Academic Accomplishment? The Case of Max Planck Directors. Max Plan Institute of Economics, Mimeo.

Campbell, E.G., Clarridge, B.R., Gokhale, M., Birenbaum, L., Hilgartner, S., Holtzman, N.A., Blumenthal, D., 2002. Data withholding in academic genetics. Journal of The American Medical Association 287 (4), 473-480.

Carayol, N., 2004. Academic incentives and research organization for patenting at a large French university. Working Paper.

Cohen, W.M., Nelson, R.R., Walsh, J.P., 2002. Links and impacts: the influence of public research on industrial R\&D. Management Science 48 (1), 1-23.

Dasgupta, P., David, P.A., 1994. Toward a new economics of science. Research Policy 23, 487-521.

David, P.A., 1998. Common agency contracting and the emergence of "open science" institutions. The American Economic Review 88 (2), 15-21.

David, P., Mowery, D.C., Steinmueller, W.E., 1992. Analysing the economic payoffs from basic research. Economics of Innovation and New Technology 2, 73-90.

Debackere, K., Veugelers, R., 2005. The role of academic technology transfer organizational in improving industry science links. Research Policy 34 (3), 321-342.
Feller, I., 1990. Universities as engines of R\&D-based economic growth: they think they can. Research Policy 19, 335-348.

Hall, B., Jaffe, A., Trajtenberg, M., 2001. The NBER patent citation data file: lessons, insights and methodological tools. NBER Working Paper (8498).

Henderson, R., Jaffe, A., Trajtenberg, M., 1998a. Universities as a source of commercial technology: a detailed analysis of university patenting, 1965-1988. Review of Economics and Statistics 80 (1), 119-127.

Henderson, R., Jaffe, A., Trajtenberg, M., 1998b. University patenting amid changing incentives for commercialization. In: Navaretti (Ed.), Creation and Transfer of Knowledge. Institutions and Incentives.

Jaffe, A., 2000. The U.S. patent system in transition: policy innovation and the innovation process. Research Policy 29, 531.

Kenney, M., Goe, W., 2003. The role of social embeddedness in professorial entrepreneurship: a comparison of electrical engineering and computer science at UC Berkeley and Stanford. Research Policy 33 (3), 691-707.

Levin, S.G., Stephan, P.E., 1991. Research productivity over the life cycle: evidence for academic scientists. The American Economic Review 81 (1), 114-132.

Looy, B.V., Callaert, J., Debackere, K., 2005. Publication and Patent Behavior of Academic Researchers: Conflicting, Reinforcing or Merely Co-existing? K.U. Lueven, Mimeo and Belgium.

Louis, K., Jones, L., Anderson, M., Blumenthal, D., Campbell, E., 2001. Entrepreneurship, secrecy, and productivity: a comparison of clinical and non-clinical faculty. Journal of Technology Transfer 26 (3), 233-245.

Mansfield, E., 1991. Academic research and industrial innovation. Research Policy 20, 1-12.

Mansfield, E., 1995. Academic research underlying industrial innovations: sources, characteristics, and financing. The Review of Economics and Statistics 77, 55-65.

Mansfield, E., 1998. Academic research and industrial innovation: an update of empirical findings. Research Policy 26, 773-776.

Meyer, M., 2006. Are patenting scientists the better scholars? An exploratory comparison of inventorauthors with the non-inventing peers in nano-science and technology. Research Policy 35, 1646-1662.

Mowery, D.C., Ziedonis, A.A., 2001. Numbers, quality, and entry: how has the Bayh-Dole Act effected U.S. university patenting and licensing? In: Jaffe, A.B., Lerner, J., Stern, S. (Eds.), Innovation Policy and the Economy 1. The MIT Press, Cambridge, Massachusetts, pp. 187-220.

Murray, F., Stern, S., 2005. Do formal intellectual property rights hinder the free flow of scientific knowledge? NBER Working Paper 11465 .

Narin, F., Hamilton, K.S., Olivestro, D., 1997. The increasing linkage between U.S. technology and public science. Research Policy 26, 317-330.

Owen-Smith, J., Powell, W.W., 2001. To patent or not: faculty decisions and institutional success at technology transfer. Journal of Technology Transfer 26, 99-114.

Remafedi, G., French, S., Story, M., Resnick, M.D., Blum, R., 1998. The relationship between suicide risk and sexual orientation: results of a population-based study. American Journal of Public Health 88 (1), 57-60.

Siegel, D.S., Waldman, D., Link, A., 1999. Assessing the impact of organizational practices on the productivity of university technology transfer offices: an exploratory study. Research Policy 32, $27-48$. 
Thursby, J.G., Thursby, M.C., 2000. Who is selling the ivory tower? The sources of growth in university licensing. NBER Working Paper (7718).

Trajtenberg, M., 2005. The mobility of inventors and the productivity of research. In: Conference presentation, NBER Summer Institute.
Trajtenberg, M., Henderson, R., Jaffe, A., 1997. Universities vs. corporate patents: a window on the basicness of innovations. Economics of Innovation and New Technology 5 (1), 19-50.

Wooldridge, J.M., 2000. A framework for estimating dynamic, unobserved effects panel data models with possible feedback to future explanatory variables. Economic Letters 68, 245-250. 